\title{
A RELAÇÃO DA EDUCAÇÃO DO CAMPO COM OS PARADIGMAS AGRÁRIOS
}

\author{
Paulo Alfredo Schönardie ${ }^{1}$
}

\begin{abstract}
Resumo
Este artigo tem a educação do campo, que está inserida no grande campo da educação popular, como objeto central. É observada uma relação direta da educação do campo com o campesinato. A educação do campo não acontece de forma independente do contexto social, mas é sim influenciada pelos paradigmas agrários, seja pelo marxista, pelo capitalista da modernização da agricultura ou pela recampesinização. Entender esta relação da educação do campo com os paradigmas agrários torna premente primeiro breves definições de educação do campo, do grande campo da educação popular e do campesinato. Posteriormente são apresentados os paradigmas agrários em sua relação com a educação e sobretudo com a educação do campo.
\end{abstract}

Palavras-chave: Educação do Campo; Campesinato; Paradigmas Agrários; Educação Popular; Recampesinização

\section{THE RELATIONSHIP OF COUNTRYSIDE EDUCATION WITH THE AGRARIAN PARADIGMS}

\begin{abstract}
This paper has the countryside education, which is inserted into the large field of popular education, as a central object. A direct relationship between countryside education and peasantry is observed. The countryside education does not happen independently from the social context, but are influenced by the agrarian paradigms such as Marxist, capitalist of

\footnotetext{
${ }^{1}$ Paulo Alfredo Schönardie é licenciado em História e Mestre em Educação nas Ciências pela UNIJUÍ e Doutor em Ciências Econômicas e Sociais (Dr. phil.) pela Universität Hamburg - UHH na Alemanha. Atualmente realiza Pós-doutorado no Programa de Pós-Graduação em Educação nas Ciências da UNIJUÍ com bolsa CAPES. É integrante do Grupo de Estudos de Educação Popular, Movimentos e Organizações Sociais - GEEP/CNPq. Endereço: UNIJUí - Mestrado e Doutorado em Educação, Rua do Comércio, 3000 Caixa Postal 560, Ijuí-RS, 98700-000. E-mail: pschonardie@gmail.com
}

Revista Reflexão e Ação, Santa Cruz do Sul, v. 25, n. 2, p. 196-214, Maio./Ago. 2017.

http://online.unisc.br/seer/index.php/reflex/index 
agriculture modernization and repeasantization. Understanding the relationship of countryside education with the agrarian paradigms turns brief definition of countryside education, the large field of popular education and peasantry. Additionally, this study presents the agrarian paradigms and their relation to education and especially with the countryside education.

Keywords: Countryside Education; Peasantry; Agrarian Paradigms; Popular Education; Repeasantization

\title{
LA RELACIÓN DE LA EDUCACIÓN DEL CAMPO CON LOS PARADIGMAS AGRARIOS
}

\begin{abstract}
Resumen
Este artículo tiene la educación del campo, que se inserta en el amplio campo de la educación popular, como objeto central. Se observó una relación directa de la educación del campo con el "campesinato". La educación del campo no se produce con independencia del contexto social, sino que está influenciada por los paradigmas agrarios, sea por el marxista, por la modernización capitalista de la agricultura y la "recampesinização". Comprender la relación entre la educación del campo con los paradigmas agrarios, hace urgente primero breves definiciones de la educación del campo, del gran campo de la educación popular y del “campesinato". Posteriormente se presentan los paradigmas agrarios en su relación con la educación y, sobre todo, con la educación del campo.
\end{abstract}

Palabras clave: Educación del Campo; "Campesinato"; Paradigmas Agrarios; Educación Popular; "Recampesinização"

\section{INTRODUÇÃO}

Nos últimos anos tem sido desenvolvida a prática e ao mesmo tempo o conceito de educação do campo. A educação do campo emerge do contexto social de luta do campesinato. Ela é constituída, portanto, a partir do reconhecimento dos camponeses como categoria social integrante e historicamente atuante na sociedade brasileira. A educação do campo vem ao mesmo tempo afirmar a existência histórica e atual dos camponeses e das camponesas, bem 
como, é um movimento de resistência à forma como a concepção modernista de educação ainda os continua tratando.

$\mathrm{O}$ campesinato brasileiro se constituiu historicamente às margens do modelo de sociedade dominante e aceita socialmente. Às margens do latifúndio, dos centros de povoamento, do poder, do Estado e desta forma, a sua realidade social não era e em grande parte não continua sendo trabalhada tanto na escola formal quanto em espaços educativos informais. É bem verdade que no Sul do Brasil, por exemplo, o Estado com os projetos de colonização oficiais dos séculos 19 e 20 contribuiu para que grande parte da população local se constituísse como camponesa. Os interesses desse tipo de colonização não visavam, entretanto, o surgimento do campesinato, pois eram de outra ordem, tais como geopolíticos e econômicos. Dominar um território e não reproduzir organicamente a categoria social camponesa com suas formas educativas foi historicamente a prática de quem detinha o poder.

De forma lenta, mas gradual, a escola e os processos educativos, sejam os pautados pelo Estado ou por instituições particulares de ensino, estão se generalizando em toda a América Latina, que ainda é uma das regiões do planeta que mais apresenta a forma de vida camponesa. A escola penetrou desta maneira também nas regiões rurais mais afastadas. Mesmo assim, como a reprodução do modo de vida camponês não era e ainda não é central para o projeto de sociedade modernista brasileiro, os processos educativos formais, inclusive em regiões rurais em que há predominância absoluta de camponeses, historicamente não levaram em conta a realidade de vida destes. Normalmente nem se discute questões agrárias nas escolas do campo, muito menos o modo de produção, de reprodução e de vida de camponesas e de camponeses é pautado. Somente pela omissão da escola, descontextualizada do meio social em que está inserida, pode-se afirmar que a condição camponesa está condenada a desaparecer. Junto desaparecem as escolas do campo. Sem dúvida, é esse um dos motivos da drástica redução do número de escolas do campo na última década no Brasil.

Durante séculos a sociedade brasileira foi completamente agrária e a maioria da população vivia na condição de camponesa. Ainda hoje, o Brasil é um dos países que apresenta expressivo número de camponeses. É paradoxal, portanto, que seu modo de vida não tenha sido, por tanto tempo, nem mesmo tema nos processos educativos formais. Para entender esse contexto paradoxal, assim como a proposta e prática da educação do campo que tem se desenvolvido nos últimos anos de forma orgânica como contraponto aos processos educativos historicamente impostos ao campesinato, é muito importante situar a sociedade brasileira, sobretudo a sociedade agrária brasileira dentro de seus grandes paradigmas agrários e estes em sua prática educativa.

Revista Reflexão e Ação, Santa Cruz do Sul, v. 25, n. 2, p. 196-214, Maio./Ago. 2017. http://online.unisc.br/seer/index.php/reflex/index 
Cientistas sociais, preocupados com a realidade social do campesinato e muitas vezes oriundos do próprio campesinato e por isso realizando análises orgânicas ao modo de vida camponês, estão, aos poucos, situando os camponeses e as camponesas na história brasileira. Assim, elevam de forma realista o campesinato à categoria social historicamente presente, bem como, reconhecem e evidenciam sua presença e importância na dinâmica social. Reconhecer os camponeses como sujeitos históricos também implica situar sua luta pela busca de autonomia dentro dos paradigmas agrários, nos quais a sociedade brasileira, sobretudo a agrária, tem se pautado.

Historicamente a ciência tem definido e analisado os paradigmas marxista e da modernização da agricultura como os dois únicos. Atualmente, entretanto, vem se desenvolvendo um novo paradigma agrário, o da recampesinização. Este sim, está em sintonia com o campesinato, oriundo inclusive da luta cotidiana de camponesas e de camponeses. Aqui está também um foco de estudo e contribuição social de cientistas sociais preocupados e comprometidos com os camponeses, ou seja, o grupo social mais presente e mais produtivo não só da sociedade brasileira, mas de toda a terra.

Desse contexto, fica evidente a hipótese de que a educação do campo é diretamente influenciada pelos paradigmas agrários. Tanto no paradigma marxista, quanto no paradigma da modernização da agricultura, nem mesmo a expressão "educação do campo" era conhecida, e com a construção da perspectiva paradigmática da recampesinização, surge e está se configurando a educação do campo como forma educativa que traz consigo práticas socialmente justas e adequadas à categoria social do campesinato.

A partir da hipótese formulada, cabe perguntar se há uma relação da educação do campo com os paradigmas agrários. Para responder este questionamento torna-se necessário percorrer, mesmo que de forma breve ${ }^{2}$, as veredas teóricas da educação do campo, da educação popular, do campesinato e dos paradigmas agrários, e neste caso a teoria marxista e suas diferentes interpretações, a teoria da modernização da agricultura e também da recampesinização. Com a tessitura destas diferentes e muitas vezes divergentes vertentes teóricas, pode-se chegar a uma formulação que compreenda a relação hipoteticamente enunciada.

\footnotetext{
2 "Breve", pois em um artigo curto não se pode aprofundar demasiado as diferentes teorias necessárias para fazer a relação entre a educação do campo e os paradigmas agrários. Pode-se buscar necessários aprofundamentos em Schönardie (2013), Arroyo et al. (2011), Antunes-Rocha, Martins (2009), Kolling et al. (2002), Streck et al. (2014), Schönardie et al. (2016a), Schönardie et al. (2016b), Van der Ploeg (2008), Tschjanow (1987), Schultz (1964), Marx (2008a; 2008b).
}

Revista Reflexão e Ação, Santa Cruz do Sul, v. 25, n. 2, p. 196-214, Maio./Ago. 2017.

http://online.unisc.br/seer/index.php/reflex/index 
O texto é assim, fruto de pesquisas ainda em andamento, que denomino hoje de grande campo de "educação popular do campo". Trata-se então de um ensaio, que apresenta uma teoria embasada na atuação junto aos movimentos do campo e esta em sua reflexividade no cotidiano de grupo específico de pesquisa na Universidade ${ }^{3}$.

Situar e entender a educação do campo em seu movimento entre e com os paradigmas agrários e sobretudo sua relação construtiva com a recampesinização demanda breves definições da categoria social do campesinato, da própria educação do campo e da relação desta com a educação popular. Também a apresentação e conceituação dos paradigmas agrários e da concepção de educação destes se faz mister, e é apresentada na sequência.

\section{CAMPESINATO E EDUCAÇÃO DO CAMPO: NOVA FORMA DE EDUCAÇÃO POPULAR}

A educação do campo, que está diretamente relacionada com o campesinato, tem se constituído como nova forma de educação popular, tendo suas raízes no grande campo da educação popular. Aqui é importante ter presente a concepção de "educação popular" como "uma prática educativa que se propõe a ser diferenciada, isto é, compromissada com os interesses e a emancipação das classes subalternas" (PALUDO, 2001, p. 82).

Historicamente, o campesinato foi e em grande parte continua sendo visto como classe ou grupo social subalterno, sobretudo, a partir dos paradigmas marxista ${ }^{4}$ e da modernização da agricultura, o que também tem relação direta com a forma de se fazer educação nesses paradigmas. O grande campo da educação popular, como ficou objetivamente colocado acima, não compartilha da condição de que o camponês seja subalterno. Muito pelo contrário, busca a emancipação de todos os grupos sociais em sua condição de sujeitos históricos e sociais.

\footnotetext{
${ }^{3}$ Parte das reflexões apresentadas nesse artigo, foram também apresentadas na X Anped Sul, realizada em Florianópolis, em Outubro de 2014. Disponível em: http://xanpedsul.faed.udesc.br/arq_pdf/280-0.pdf. Acessado em: 06 de Julho. 2018.

${ }^{4}$ É ousado afirmar que o campesinato foi historicamente visto como classe subalterna no marxismo. Análises mais profundas da teoria marxista predominante evidenciam essa afirmativa. A maioria dos autores, no entanto, se pautam na dualidade entre marxismo e capitalismo, assim como o fazem Fernandes et al. (2014), o que me parece ser uma simplificação do marxismo. Conforme será abordado em sessão mais abaixo, há diferentes vertentes da teoria marxista, tais como a de Kautsky e a de Tschajanow, que mais interessam na análise aqui em curso. Na análise mais abaixo também se entenderá a afirmação de que na variante marxista predominante o campesinato esteja condenado à extinção. Considero ainda que o debate marxista sobre o campesinato e sua relação com a educação pode ser ampliado com a perspectiva proposta por Antonio Gransci (2006), o que provoca a continuidade das pesquisas aqui trazidas no texto.
}

Revista Reflexão e Ação, Santa Cruz do Sul, v. 25, n. 2, p. 196-214, Maio./Ago. 2017.

http://online.unisc.br/seer/index.php/reflex/index 
As práticas de educação popular buscam a constituição de sujeitos populares "capazes de serem os construtores da sua própria história de libertação" (PALUDO, 2001, p. 99). Daqui emerge a autonomia dos protagonistas envolvidos, e consequentemente a autonomia de seu grupo social. Está-se aqui em consonância com a concepção da pedagogia da autonomia de Paulo Freire (2002). Sujeitos camponeses e um campesinato autônomos são, assim, centrais para a educação popular.

De acordo com Paludo (2001) a educação popular está em busca de alternativas. E uma destas alternativas, a da construção de uma sociedade emancipadora, vem se construindo nos últimos anos. Trata-se da educação do campo, que inserida no grande campo da educação popular, também se vale em muito do arcabouço teórico desta. Ou seja, busca a inserção social e autonomia das camponesas e dos camponeses a partir de seu cotidiano. Isto significa partir da condição camponesa, isto é, alçar o modo de vida camponês tradicional ao centro das atenções. Desta forma se está, mais do que reconhecendo a prática camponesa do dia a dia, reconhecendo o campesinato como categoria social.

A educação do campo, portanto, parte do reconhecimento da categoria social camponesa. Daqui emerge uma questão a ser entendida, ou seja, é necessário, ainda que de forma sucinta, uma definição de campesinato.

O campesinato foi durante milênios onipresente (SCHÖNARDIE, 2013) e por isso não interessava teoricamente. Onipresente, pois não era questionado nem como modo de vida, nem como modo de produção. Era espaço de vivências. Somente durante a Revolução Industrial e sua consequente e posterior Modernização da Agricultura passou a ser questionado e condenado, mas ao mesmo tempo estudado. É, portanto, ainda um campo novo de estudo, trazido primeiramente por Marx (2008a; 2008b) e seus seguidores como Kautsky (1902) e Tschajanow (1987). E, ao mesmo tempo em que deixado de lado como categoria importante e inclusive considerado a ser superado pelos teóricos da modernização como Schultz (1964), Roggers (1962), Banfield (1958) e Foster (1974), paradoxalmente é estudado pelos mesmos. A linha de estudos dominante a partir da modernização da agricultura foi e continua sendo, entretanto, a percepção de que o camponês está em extinção. E para a concepção da modernização da agricultura é inclusive um obstáculo a ser superado. Logo não pautá-lo em processos educativos formais passa a ser estratégico.

O conceito de campesinato é, portanto, ainda novo, em construção, e vem sendo ressignificado atualmente a partir do paradigma da recampesinização da agricultura. É ao mesmo tempo complexo e difícil de ser definido, pois as práticas camponesas se apresentam de forma diversa em diferentes regiões da terra. Não só o conceito de campesinato, mas Revista Reflexão e Ação, Santa Cruz do Sul, v. 25, n. 2, p. 196-214, Maio./Ago. 2017.

http://online.unisc.br/seer/index.php/reflex/index 
também a própria categoria social campesina está em constante reconstrução histórica. $\mathrm{Ou}$ seja, nem o conceito, nem o camponês como tal são estáticos. Mesmo assim, e obviamente, a partir da concepção e dos estudos do grande campo popular, seja pelo viés da educação ou não, o campesinato pode ser claramente definido por meio de algumas características peculiares.

Para Schönardie (2013) são três as características básicas que dão identidade mínima aos camponeses: primeiro, a família de agricultoras e de agricultores camponeses tem o soberano controle da gestão de sua unidade de produção. Ou seja, todas as decisões sobre o que, como, quanto e quando produzir estão sob controle dos camponeses envolvidos. A produção de alimentos de forma saudável é central. Desse processo emerge também a soberania alimentar. Em segundo lugar, a base da força de trabalho aplicada na propriedade rural provém da família de agricultores e agricultoras. E em terceiro lugar, os meios de produção, incluindo a terra, são de propriedade da família.

Sob esse arcabouço do campesinato que se pauta a educação do campo. O desenvolvimento histórico do saber campesino e do próprio campesinato passam a ser a base de uma educação do campo que recoloca os camponeses como sujeitos da história. Daqui emerge outro grande campo de questionamento. Trata-se de procurar entender o que é a educação do campo.

Inicialmente é preciso ter presente que o significado de 'educação do campo' ainda é incipiente e por isso mesmo muito difícil de definir. Educação do campo é um conceito novo, mas que leva em consideração o processo educativo por meio do saber tradicional, do saber campesino. Não somente o conceito de educação do campo é novo e ainda não definido por completo, a própria expressão "educação do campo" é relativamente nova. Para Fernandes (2005) o surgimento da perspectiva da educação do campo ainda não tinha 10 anos em 2005. Ou seja, a educação do campo vem sendo pautada a menos de duas décadas, o que é um período muito curto sob o ponto de vista da historiografia, mas mesmo assim, nesse curto período, foram configuradas linhas conceituais básicas da educação do campo. A terminologia 'educação do campo' tem uma de suas origens no PRONERA - Programa Nacional de Educação na Reforma Agrária, do MDA - Ministério do Desenvolvimento Agrário. De acordo com Freitas (2011) pode-se afirmar que a educação do campo tem assim uma ligação direta com os movimentos sociais populares, tais como aqueles que lutam pela reforma agrária. Molina e Freitas (2011) observam que os debates sobre a educação do campo têm sido concentrados no que desenvolver nas escolas rurais, com foco centrado na redução das desigualdades no campo. E, de forma recente, as universidades públicas brasileiras têm Revista Reflexão e Ação, Santa Cruz do Sul, v. 25, n. 2, p. 196-214, Maio./Ago. 2017.

http://online.unisc.br/seer/index.php/reflex/index 
direcionado preocupações e ações para com a educação do campo, tais como a criação de cursos multidisciplinares voltados às populações camponesas e suas realidades e necessidades. Também se constituem cada vez mais grupos de pesquisadores, que a partir do compromisso social, fazem da educação do campo seus focos de pesquisas.

Pautar e agir de acordo com os preceitos da educação do campo não é, no entanto, apenas uma realidade somente do Brasil. Toda a América Latina tem contribuído de forma incisiva no desenvolvimento da educação do campo, como mostram Baronnet (2011), a partir da prática educativa campesina dos zapatistas em Chiapas no México, e Cragnolino (2011), com base nos processos educativos historicamente vivenciados pelo campesinato na região de Córdoba na Argentina. As práticas de resistência do campesinato podem ser também observadas em todos os outros continentes, como por exemplo, entre os camponeses que pautam suas atividades na produção orgânica e de permacultura na Áustria ou entre os camponeses alemães que se baseiam em preceitos ecológicos. No Brasil especificamente e na América Latina como um todo, há, no entanto, o pioneirismo de teorizar as questões ligadas ao modo de vida camponês, tais como a educação do campo e a própria educação popular. Consequentemente o processo reflexivo nesta região geográfica tem contribuído de forma significativa com a resistência popular campesina.

Pela educação do campo, estão assim refletidas as lutas dos movimentos sociais do campo. Desta maneira, fica evidente, tanto a relação da educação do campo com a educação popular quanto sua origem a partir das preocupações e práticas da educação popular.

A educação do campo emerge assim do contexto social de necessidade do campesinato, mas a sua construção inicial e ainda atual tem uma profunda ligação com programas governamentais, sejam de inserção econômica dos envolvidos, por exemplo, em processos de reforma agrária, sejam de cunho educativo. Não restam dúvidas que o atual interesse e ação do Estado, focando ações também na educação do campo, é muito positivo e está gerando frutos. Mas ainda há um longo caminho até uma definição consistente e consequente da prática educativa nessa concepção, que a meu ver também precisa se libertar de uma excessiva proximidade estatal. É importante lembrar que o Estado paradoxalmente foi e ainda é o maior responsável pela modernização da agricultura, e agora também um dos propulsores da educação do campo.

A educação do campo agrega uma perspectiva histórica libertadora que precisa, com base em Freire (1992), ser praticada no diálogo. A perspectiva libertadora de emancipação e construção de consciência do campesinato perante a sociedade e com a afirmação de sua condição camponesa precisa acontecer num movimento de libertação tanto do paradigma Revista Reflexão e Ação, Santa Cruz do Sul, v. 25, n. 2, p. 196-214, Maio./Ago. 2017.

http://online.unisc.br/seer/index.php/reflex/index 
marxista - ou da ideia predominante neste - quanto do ideário impositivo de exclusão provindo do paradigma da modernização da agricultura. Numa perspectiva de autonomia do campesinato, o paradigma da recampesinização, que será analisado mais abaixo, e que também tem a autonomia camponesa como um dos focos a serem alcançados, pode contribuir significativamente para a prática da educação do campo. Entender esses paradigmas e suas concepções de educação passa a ser premente.

\section{OS PARADIGMAS MARXISTA E DA MODERNIZAÇÃO DA AGRICULTURA E A EDUCAÇÃO "NO" CAMPO}

As origens da conceituação de campesinato estão nas análises sociais e econômicas de Karl Marx. Esta afirmação é ousada e ao mesmo tempo não compreendida, tanto devido a uma interpretação errônea de Marx, quanto pelo fato de sua teoria ter sido relegada ao segundo plano pela sociedade ocidental, pautada em um projeto modernista baseado no capitalismo, da qual fazemos parte.

Marx, em sua obra, sobretudo com Das Kapital (O capital), fez mais que construir um dos grandes paradigmas que regem a humanidade. Ele também lançou as bases para os estudos camponeses. Analisando a sociedade da Revolução Industrial de forma crítica, foi o primeiro a admitir os camponeses como classe social independente e necessária para o sucesso da sociedade capitalista (MARX, 2008a, p. 78), a qual ele criticava ${ }^{5}$.

Mesmo que Marx tenha concentrado suas análises na sociedade industrial e tratado de forma superficial da sociedade rural, ele teve a percepção primordial de reconhecer o camponês como tal. Isso se dá, pois antes dos estudos de Marx e da Revolução Industrial, os camponeses eram onipresentes, ou seja, não eram confrontados com um modo produtivo e

\footnotetext{
${ }^{5}$ Sei que minha interpretação pode parecer contraditória para a maneira errônea como os escritos de Karl Marx são interpretados tanto dentro quanto fora do Brasil. Outras tantas vezes há problemas de tradução dos escritos de Marx, não sendo possível interpretações coerentes. Por isso tenho buscado o texto original em língua alemã, do qual cito do original a passagem que considero a mais importante. Desta forma espero provocar o debate e ao mesmo tempo orientar o leitor numa linha de interpretação de Marx mais fiel ao texto original: "Privateigentum, als Gegensatz zum gesellschaftlichen, kollektiven Eigentum, besteht nur da, wo die Arbeitsmittel und die äußeren Bedingungen der Arbeit Privatleuten gehören. Je nachdem aber diese Privatleute die Arbeiter oder die Nichtarbeiter sind, hat auch das Privateigentum einen andern Charakter. Das Privateigentum des Arbeiters an seinen Produktionsmitteln ist die Grundlage des Kleinbetriebs, der Kleinbetrieb eine notwendige Bedingung für die Entwicklung der gesellschaftlichen Produktion und der freien Individualität des Arbeiters selbst. Allerdings existiert diese Produktionsweise auch innerhalb der Sklaverei, Leibeigenschaft und andrer Abhängigkeitsverhältnisse. Aber sie blüht nur, schnellt nur ihre ganze Energie, erobert nur die adäquate klassische Form, wo der Arbeiter freier Privateigentümer seiner von ihm selbst gehandhabten Arbeitsbedingungen ist, der Bauer des Ackers, den er bestellt, der Handwerker des Instruments, worauf er als Virtuose spielt"“(MARX, 2008a, p. 789).
}

Revista Reflexão e Ação, Santa Cruz do Sul, v. 25, n. 2, p. 196-214, Maio./Ago. 2017. http://online.unisc.br/seer/index.php/reflex/index 
organizacional diferente, como foi a partir do processo de industrialização ainda em formação à época da análise de Marx.

Aqui é muito importante desconstruir uma outra ideia completamente falha da perspectiva paradigmática inaugurada por Marx. A de que os camponeses são "sacos de batatas". Marx citou sim a expressão "saco de batatas" em alusão aos camponeses em uma análise específica da Revolução Francesa (MARX, 1988). Naquela ocasião ele analisava um acontecimento histórico muito específico e a maneira como ele usa as palavras nesse texto não pode ser transpassada para uma análise generalizada da sociedade. A questão central é a de como evoluíram a recitação, reinterpretação e desenvolvimento do paradigma marxista. Este processo tomou dois caminhos distintos: um com Karl Kautsky e outro com Alexander Tschajanow.

Karl Kautsky (1902) não levou em consideração que Marx reconheceu o campesinato como integrante e importante na dinâmica social. Ele, usando o arcabouço marxista de análise industrial, simplesmente alargou a teoria para a agricultura. A consequência foi a de que os camponeses precisariam ser transformados em proletários industriais. É importante ter presente que Kautsky escreveu em um contexto histórico específico de industrialização e necessidade de trabalhadores na indústria na Alemanha. Por outro lado, seu texto era o programa de um partido político específico, que queria mais proletários como votantes. Pensava ele, os camponeses estarem distantes de sua linha partidária.

O problema que se põe está relacionado ao fato da interpretação errônea e ao mesmo tempo continuidade do desenvolvimento do arcabouço marxista por Kautsky ter se tornado a base da teoria marxista, seja ela no ocidente interessado em extinguir os camponeses, seja nos países ditos socialistas, que com a planificação, também concentraram as terras com um processo de expropriação e proletarização dos camponeses. A prática da educação do campo nem era cogitada. Duas eram, entretanto, as ações educativas propostas por Kautsky: ensinar aos camponeses o trabalho industrial e, na agricultura, as modernas técnicas industriais aos grandes proprietários. Os camponeses não estariam preparados para estas técnicas. O resultado seria a morte do indesejado campesinato (KAUTSKY, 1902).

Um viés diferente da teoria marxista foi inaugurado por Tschajanow. Para ele era necessário trabalhar com os camponeses, ou seja, partir do contexto social dos camponeses, o que já de antemão mostra coesão com a educação do campo. Tschajanow propôs muito cedo, na Rússia revolucionária, um modelo de extensão rural que introduziria sim algumas técnicas necessárias para melhorar a vida dos camponeses, sobretudo para reduzir a penosidade do trabalho (TSCHAJANOW, 1987), mas que sempre levassem em consideração as práticas Revista Reflexão e Ação, Santa Cruz do Sul, v. 25, n. 2, p. 196-214, Maio./Ago. 2017. http://online.unisc.br/seer/index.php/reflex/index 
cotidianas camponesas. Para ele os camponeses não são uma categoria estática, por isso não haveria uma cultura camponesa homogênea e única (TSCHAJANOW, 1987), e como a sociedade também está em constante transformação, seria importante introduzir algumas melhorias, por vezes técnicas, por meio de um processo educativo, que teria na extensão rural seu instrumento. Mas, tratava-se de um processo educativo que sempre partiria do princípio da difusão e adaptação dos saberes tradicionais camponeses.

Tschajanow e suas ideias e práticas, também de arcabouço marxista, como não em sintonia com a planificação soviética foi preso e condenado. Já no ocidente havia uma barreira para todo tipo de prática e teorização que vinha do campo soviético. O resultado é que foi deixado de lado por décadas. Atualmente, tem servido como uma das bases para a construção do paradigma da recampesinização. Ao mesmo tempo sua experiência concreta em fazer educação junto e a partir do conhecimento tradicional camponês pode ser considerada uma das raízes da educação do campo. Um aprofundamento do debate a partir de Tschajanow é, por um lado ainda um campo aberto, e por outro lado, uma possibilidade muito grande de contribuição para o desenvolvimento da educação do campo.

No ocidente, consequentemente no Brasil, o paradigma predominante foi o capitalista da modernização da agricultura, ou simplesmente 'modernização da agricultura'. Sua ação, baseada fortemente no que se pode chamar de educação 'no' campo foi fortemente planejada 6 . Foram escolhidos alguns países e regiões para ser implantado primeiro, e por mais paradoxal que possa parecer, uma dessas regiões foi o Sul do Brasil, aonde há historicamente predominância de camponeses, sendo que pela sua prática gera exclusão do meio rural.

De forma bastante sucinta, a modernização da agricultura nada mais é do que a introdução de práticas de produção capitalistas na agricultura (SCHÖNARDIE, 2013). Tanto os métodos quanto os insumos de produção passam a ser introduzidos a partir de fora da unidade produtiva. Isso também passou a ser aplicado ao camponês. Nesse processo se configuram círculos de dependência, nos quais os agricultores, sejam eles camponeses ou não, perdem sua autonomia e por final são condenados a serem incorporados por algum capitalista que se sobressaiu. Para Tambara (1985), a modernização da agricultura nada mais é do que a penetração capitalista na agricultura. Nesta perspectiva pode-se afirmar que a modernização da agricultura provocou destruição ambiental e exclusão econômica e social. O modo de vida camponês, seu processo reprodutivo e as formas camponesas tradicionais de educação passam, assim, a ser rapidamente destruídas.

\footnotetext{
${ }^{6} \mathrm{O}$ que denomino aqui de educação "no" campo, entendo como sinônimo de educação rural. Revista Reflexão e Ação, Santa Cruz do Sul, v. 25, n. 2, p. 196-214, Maio./Ago. 2017. http://online.unisc.br/seer/index.php/reflex/index
} 
Com base na ideia de que tanto o camponês tradicional, quanto o agricultor que passou pelo processo de modernização serem racionais e objetivarem o lucro, Theodore Schultz se projetou como o grande teórico da modernização da agricultura. Para Schultz a agricultura tradicional é pouco eficiente (SCHULTZ, 1964) e desta forma não consegue o lucro. Schultz, dentro de uma perspectiva capitalista, apresenta a solução para sua interpretação, o que sistematiza no livro Transforming traditional agriculture (SCHULTZ, 1964). Nessa obra ele descreve o que chama de problema, ou seja, o agricultor camponês tradicional, e apresenta a solução, que nada mais é do que apresentar e implantar os pacotes tecnológicos da modernização da agricultura. A revolução verde passa a ser apontada como solução. $\mathrm{Na}$ prática, isso significava o apontamento da necessidade da agricultura tradicional usar fatores de produção externos a sua unidade produtiva, o que ao mesmo tempo provocou dependência do capital e perda de autonomia, até a perda de sua terra e consequentemente de sua existência. O próprio Schultz já previa isto.

A questão que se punha era como fazer com que o camponês mudasse seu modo de produzir e consequentemente viver. Tratava-se de uma questão educativa. Aqui a resposta foi dada, ainda na gênese do processo de modernização, por Everett Rogers. Ele apresentou a sua concepção no livro Diffusion of Innovations (1962). Para ele a difusão de inovações, que nada mais eram do que os pacotes tecnológicos da modernização da agricultura, deveriam ser difundidos por extensionistas em programas oficiais de extensão rural. A consequência foi a criação de instituições extensionistas em boa parte dos países, e no Brasil e sobretudo no Sul do país essa prática foi testada em forma de projeto piloto com a "operação tatu". O resultado foi a dita modernização nos anos 1960 e 1970 com a monocultura da soja, que muito para além de destruição e poluição ambiental, provocou êxodo, pobreza e exclusão social.

Essas ditas novas tecnologias foram apresentadas pelo arcabouço estrutural da extensão rural oficial com uma série de condicionantes aos agricultores. A pré-condição para acessar, por exemplo, um financiamento era a de aplicar todo o pacote da modernização, ou seja, comprar sementes, adubos químicos, máquinas agrícolas, venenos e aceitar a recomendação técnica e vender toda a produção, para pagar os empréstimos no banco obviamente. Fica objetiva a conjuntura de imposição vivida pelos camponeses, em boa parte dos casos analfabetos literais, e muito mais que isso, sem ter o conhecimento da reflexão crítica relativa à ilusão que lhes era apresentada. Mesmo de forma impositiva, a vivência em um contexto de modernização passou a educar os camponeses para um pensamento capitalista.

A extensão rural passou a ser a porta de entrada da difusão de tecnologias nocivas aos camponeses. Trouxe consigo um processo educativo de imposição. Tanto pela recomendação Revista Reflexão e Ação, Santa Cruz do Sul, v. 25, n. 2, p. 196-214, Maio./Ago. 2017. http://online.unisc.br/seer/index.php/reflex/index 
técnica individual, quanto pela coletiva, como em dias de campo, em que essas tecnologias externas ao modo de vida camponês eram apresentadas como perfeitas, estava presente um processo de educação “no” campo. Tudo muito diferente da educação ‘do’ campo. Ou seja, o conhecimento tradicional do camponês, aquele em sintonia com seu modo de vida, é visto como descartável e necessário de ser superado pelos processos de educação "no" campo. A consequência, na prática, foi a do êxodo rural em massa além de um êxodo da forma camponesa de se viver, que a história recente mostrou. Cabe aqui voltar à analogia do 'saco de batatas'. Tanto o paradigma agrário marxista reelaborado por Kautsky, quanto o paradigma capitalista da modernização da agricultura são um mesmo 'saco de batatas', ou seja, condenam o campesinato a ser extinto. E para extingui-lo tem em sua gênese e aplicação um processo educativo, mas um processo educativo de imposição de tecnologias, seja de reeducação para o proletariado industrial como propõe Kautsky, ou de transformação capitalista por processos de modernização. Não considerar o saber campesino é fazer educação ‘no’ campo, isto é, educação rural, que subordina o camponês à lógica do atraso, por meio de uma modernização conservadora.

\section{RECAMPESINIZAÇÃO E EDUCAÇÃO DO CAMPO}

As prognoses e objetivos dos paradigmas marxista e da modernização da agricultura não foram confirmados de forma absoluta. Uma parte do campesinato resistiu, continuou mantendo boa parte do modo de vida camponês, mesmo que tenha incorporado também algumas práticas provindas do processo de modernização da agricultura, o que é natural, pois um certo grau de mecanização, também no dia a dia dos camponeses, pode representar diminuição da penosidade do trabalho, e além do mais o campesinato, como a sociedade em geral, não é estático.

É real, sim, que parte dos camponeses perdeu sua terra e consequentemente seu modo de vida, o que é observado, por exemplo, no êxodo rural. Mas, camponeses e camponesas continuam presentes, e como já enunciado acima, resignificando o conceito que se tem sobre e com eles e ao mesmo tempo reorganizando o modo de vida camponês. Tanto que o conceito de campesinato está sendo ampliado na atualidade pelo paradigma agrário da recampesinização, que por sua vez também ainda está em construção, mas emerge da realidade social de luta pela autonomia do campesinato. A recampesinização é ao mesmo tempo fruto da ação cotidiana de camponesas e de camponeses e reação às formas de dependência impostas a estes, seja pela prática em sociedades que adotaram o paradigma Revista Reflexão e Ação, Santa Cruz do Sul, v. 25, n. 2, p. 196-214, Maio./Ago. 2017.

http://online.unisc.br/seer/index.php/reflex/index 
marxista - entenda-se libertação de amarras estatais -, seja naquelas que se pautam no paradigma capitalista da modernização da agricultura - entenda-se libertação do capital e do Estado. De antemão cabe destacar que pela primeira vez em um paradigma agrário o sujeito camponês é o centro do paradigma e o próprio paradigma parte do campesinato.

O conceito básico de recampesinização é sistematizado por Ploeg (2008), e aos poucos vem sendo ampliado em estudos, também a partir do Sul do Brasil, mas que sempre partem da realidade social em foco. Vale lembrar que a recampesinização é uma construção recente, que parte da prática social do campesinato. E a ciência está, aos poucos, a partir de pesquisadores comprometidos com essa realidade social, procurando significar esse novo paradigma. A recampesinização traz consigo a condição camponesa, que de acordo com Ploeg (2008, p. 40), tem como características fundamentais:

(1) a luta por autonomia que se realiza em (2) um contexto caracterizado por relações de dependência, marginalização e privações. Essa condição tem como objetivo e se concretiza em (3) a criação e desenvolvimento de uma base de recursos auto-controlada e auto-gerenciada, a qual por sua vez permite (4) formas de coprodução entre o homem e a natureza viva que (5) interagem com o mercado, (6) permitem a sobrevivência e perspectivas de futuro e (7) se realimentam na base de recursos e a fortalecem, melhorando o processo de co-produção e fomentando a autonomia e, dessa forma (8) reduzem a dependência. Dependendo das particularidades da conjuntura socioeconômica dominante, a sobrevivência e o desenvolvimento de uma base de recursos própria poderão ser (9) fortalecidos através de outras atividades não agrícolas. Finalmente, existem (10) padrões de cooperação que regulam e fortalecem essas inter-relações.

Na construção do paradigma da recampesinização o ponto de partida é obviamente a condição de vida dos camponeses. Isso significa que as formas históricas de vida e produção usadas pelos camponeses, em outras palavras, os conhecimentos camponeses, são centrais. Por outro lado, a recampesinização se constrói em um contexto em que os camponeses já absorveram práticas oriundas de processos de modernização. Dessa maneira também aceita e incorpora algumas práticas provindas desta como, por exemplo, alguns processos de mecanização, como evidenciado anteriormente. Seria inclusive um retrocesso pensar em voltar a um passado idílico, que, aliás, nunca existiu. Tanto o campesinato, quanto a sociedade em geral estão em constante movimento. Do contrário, também não haveria sentido nos processos educativos.

A recampesinização, da mesma forma como a educação do campo, se caracteriza centralmente como uma luta por autonomia, ou seja, evidenciando de forma orgânica o camponês como sujeito de sua condição, como protagonista de processos sociais. Isso nos remete também a Paulo Freire (1992), que já na década de 1960, antes mesmo de se imaginar 
conceituação para o termo e a prática da educação do campo, bem como antes de se configurar a recampesinização, deixa evidente que é possível fazer uma prática educativa do campo que vá para além de um arcabouço modernista. Ou seja, de que é possível ter um processo dialógico a partir dos conhecimentos camponeses tradicionais, com base em uma educação popular que é libertadora e não apenas difusionista de tecnologias externas ao contexto camponês.

Freire (2002, p. 52) ainda nos mostra que "ensinar não é transferir conhecimento, mas criar as possibilidades para a sua própria produção ou a sua construção.” Aqui ele está em sintonia com a educação do campo, que tem um claro sentido de autonomia do educando, que a partir de sua realidade e condição social, ressignifica a si próprio e ao seu grupo social. A recampesinização também tem por objetivo a reconstrução humanizante do campesinato, que em busca constante por autonomia perante as adversidades cotidianas que se apresentam, procura a ação consciente de camponeses e de camponesas.

Pode-se afirmar que a educação do campo emerge em um contexto de recampesinização e contribui, ao mesmo tempo, para o aprofundamento desse movimento de recampesinização, que por sua vez também contribui para a expansão dos processos educativos do campo. $\mathrm{O}$ campesinato, o paradigma da recampesinização e a educação do campo vão se transformando e ressignificando, mas sempre com a realidade social camponesa e os próprios sujeitos camponeses e camponesas ao centro e como sujeitos conscientes da história que vivenciam.

\section{ALGUMAS CONSIDERAÇÕES}

A educação do campo está sendo construída por camponesas e camponeses, cientistas sociais, professoras e professores, desde o ensino mais elementar, preocupados com um processo educativo que não seja impositivo, que seja dialógico e que tenha seu ponto de partida e também de chegada na problematização da realidade social e consequentemente na conscientização do campesinato. Pela educação do campo acontece a afirmação da categoria social camponesa, não só como historicamente integrante da sociedade, mas como protagonista desta. A educação do campo passa a ter o potencial de ser significante e constituinte de um modo de vida, da condição camponesa, do campesinato.

A educação do campo não acontece independente da sociedade. Ela é diretamente influenciada pelos paradigmas agrários presentes na sociedade. Pode-se afirmar que os paradigmas agrários tem inclusive o poder de definir se aceitam ou não a prática da educação do campo. O paradigma marxista em sua linha dominada por Kautsky - a predominante no Revista Reflexão e Ação, Santa Cruz do Sul, v. 25, n. 2, p. 196-214, Maio./Ago. 2017.

http://online.unisc.br/seer/index.php/reflex/index 
ocidente e no oriente - e também o paradigma capitalista da modernização da agricultura admitem apenas a educação 'no' campo, ou seja, a difusão de inovações produzidas fora do contexto social campesino. Há sim processos educativos ligados a esses dois paradigmas, de imposição, que visam extinguir o campesinato.

Já no paradigma da recampesinização, que está se constituindo na contemporaneidade a partir do contexto social do campesinato, todas as atenções estão voltadas para a educação do campo, que também emerge desse mesmo contexto social complexo. Tanto os processos educativos do campo, quanto o paradigma da recampesinização visam à autonomia das camponesas e dos camponeses, seja como sujeitos, seja como grupo social. O paradigma agrário da recampesinização é assim espaço por excelência da educação do campo. A educação do campo contribui para a formação do paradigma da recampesinização, ao mesmo tempo em que este contribui no desenvolvimento e significação da própria educação do campo.

Mas é importante ter presente que o paradigma da modernização da agricultura continua sendo o predominante em nossa sociedade ocidental, mesmo nas regiões camponesas do sul do Brasil. Processos educativos que não levam o campesinato em consideração estão assim presentes no dia a dia camponês. Modernização da agricultura e recampesinização são dois processos concomitantes na atualidade. Com o desenvolvimento da recampesinização, surge, no entanto, uma alternativa para a continuidade orgânica do campesinato. E, o desenvolvimento e prática da educação do campo é instrumento e caminho para a reconfiguração social da condição camponesa.

Há, ainda, longos caminhos a serem percorridos pela ciência, tanto para entender, quanto para significar o campesinato, a recampesinização e os processos educativos ligados aos mesmos, sobretudo a educação do campo. Estudar o campesinato e o paradigma da recampesinização implica reconhecer os camponeses como sujeitos de sua história. E isso nos remete automaticamente à educação do campo, que parte da mesma perspectiva. As definições de campesinato, de recampesinização e também de educação do campo, além de não serem estáticas, ainda estão em uma fase incipiente de construção. Desta maneira, a reflexão aqui proposta é apenas uma parte muito pequena destes campos de estudo. O debate continua, assim, aberto.

A educação do campo está inserida dentro do grande campo da educação popular, que busca sujeitos populares capazes de construir sua própria história de libertação, sua 
autonomia, sua condição camponesa. A educação do campo é desafio contemporâneo de todas e todos.

\section{REFERÊNCIAS}

ANTUNES-ROCHA, M. I.; MARTINS, A. A. (Org.). Educação do campo - desafios para a formação de professores. Belo Horizonte: Autêntica, 2009.

ARROYO, M. G.; CALDART, R. S.; MOLINA, M. C. (Org.). Por uma educação do campo. Petrópolis: Vozes, 2011.

BANFIELD, E. The Moral Basis of a Backward Society. Glencoe, Illinois/Chicago: The Free Press/Research Center in Economic Development and Cultural Change, 1958.

BARONNET, B. Autonomía educativa zapatista: hacia una pedagogia de la liberación. In: Em Aberto, Brasília: INEP, v.24, n.85, 2011.

CRAGNOLINO, E. El acceso a la educación básica rural en familias campesinas de Córdoba (Argentina) como resultados de múltiples historias. In: Em Aberto, Brasília: INEP, v.24, n.85, 2011.

FERNANDES, B. M. Os campos da pesquisa em educação do campo. Espaço e território como categorias essenciais, 2005, Brasília I Encontro Nacional de Pesquisa em Educação do Campo, 2005.

FERNANDES, B. M.; WELCH, C. A.; GONÇALVES, E. C. Os usos da terra no Brasil. Debates sobre políticas fundiárias. São Paulo: Cultura Acadêmica, 2014.

FOSTER, G. M. La sociedad campesina y la imagem del bien limitado. In: BARTOLOMÉ, L. J.; GOROSTIAGA, E. E. (Org.). Estudios sobre el campesinato latinoamericano. La perspectiva de la antropologia social. Buenos Aires: Ediciones Periferia, 1974.

FREIRE, Paulo. Extensão ou Comunicação? 10. ed. Rio de Janeiro: Paz e Terra, 1992. Pedagogia da Autonomia: saberes necessários à prática educativa. 25 ed. São Paulo: Paz e Terra, 2002.

FREITAS, H. C. A. Rumos da Educação do Campo. In: Em Aberto, v.24, n.85. Brasília: INEP, 2011.

GRANSCI, A. Cadernos do cárcere. v. 2, Rio de Janeiro: Civilização Brasileira, 2006.

KAUTSKY, K. Die Agrarfrage. Eine Uebersicht Uber Die Tendenzen Der Modernen Landwirtschaft Und Die Agrarpolitik Der Sozialdemokratie. Stuttgart: Dietz, 1902.

KOLLING, J. K.; CERIOLI, P. R.; CALDART, R. S. Educação do campo. Identidade e políticas públicas. Brasília: Articulação Nacional Por uma Educação do Campo, 2002. 
MARX, K. Das Kapital. Erster Band. In: Marx Engels Werke, Bd. 23, 23. Auflage. Berlin: Dietz Verlag, 2008a.

MARX, K. Das Kapital. Dritter Band. In: Marx Engels Werke, Bd. 25, 16. Auflage. Berlin: Dietz Verlag, 2008b.

MARX, K. Der achtzehnte Brumaire des Louis Bonaparte. In: Marx Engels Werke, Bd. 8, 8. Auflage. Berlin: Dietz Verlag, 1988.

MOLINA, M. C.; FREITAS, H. C. A. Avanços e desafios na construção da Educação do Campo. In: Em Aberto, Brasília: INEP, v.24, n.85, 2011.

PALUDO, C. Educação popular em busca de alternativas. Uma leitura desde o campo democrático e popular. Porto Alegre: Tomo Editorial, 2001.

PLOEG, J. D van der. Camponeses e impérios alimentares. Lutas por autonomia e sustentabilidade na era da globalização. Porto Alegre: Editora da UFRGS, 2008.

ROGERS, E. M. Diffusion of Innovations. New York: The Free Press, 1962.

SCHÖNARDIE, P. A. Bäuerliche Landwirtschaft im Süden Brasiliens. Historische, theoretische und empirische Studie zu Ernährungssouveränität, Modernisierung, Wiederbelebung und Staatsfunktion. München: Oekom, 2013.

SCHÖNARDIE, P. A.; ANDRIOLI, L. A.; FRANTZ, W. (Org.) Educação popular e políticas públicas. Reflexões a partir de diferentes lugares e olhares. Ijuí: Ed. Unijuí, 2016a.

SCHÖNARDIE, P. A.; PILLATT, L. R. B.; SILVA, S. P. (Org). Sociedade brasileira e educação. Olhares interpretativos. Ijuí: Ed. Unijuí, $2016 \mathrm{~b}$.

SCHULTZ, T. W. Transforming Traditional Agriculture. New Haven/London: Yale University Press, 1964.

STRECK, D. R. et al. Educação popular e docência. São Paulo: Cortez, 2014.

TAMBARA, E. RS: modernização e crise na agricultura. Porto Alegre: Mercado Aberto, 1985.

TSCHAJANOW, A. W. Die Lehre von der bäuerlichen Wirtschaft. Versuch einer Theorie der Familienwirtschaft im Landbau. Frankfurt/New York: Campus, 1987. 